\title{
Knowledge of Reproductive Health among School Going Adolescents Girls
}

\author{
Breme Pavithra $^{1}$, Dr. M. Senthil ${ }^{2 *}$
}

\section{ABSTRACT}

Introduction: Issues affecting adolescent reproductive and sexual health are similar to those adults, but may include additional concerns about teenage pregnancy and lack of adequate access to information and health services. Worldwide, around 16 million adolescent girls give birth every year, mostly in low-and middle-income countries. Aim: The objective of this study was to see the knowledge of reproductive health among school going adolescents girls. Materials and Methods: The sample comprising of 50 respondents of school going adolescents girls and used lottery method by adopting simple random sampling technique from the class of VIII, IX and XI(number 120). A pre structure questionnaire was used to collect the data from the respondents. The pre structured questionnaire was designed especially with the objective of the study. The questionnaire consists of 28 questions and it has consists of the following segments: Part - I: Socio-economic and Demographic variables. Part - II: Awareness level about puberty. Part - III: Awareness level about sexual transmitted diseases. Part - IV: Health problem during puberty. Results: The socio-demographic details revealed that a majority of respondents were in the age group of 16 years (32\%), class 11 (40\%), Hindu in religion (90\%), from urban background (92\%), from nuclear family (80\%), and majority of the respondents fathers occupation were unskilled labours (80\%). Age of the respondents and their knowledge on puberty, constitute 38 respondents said YES and 12 respondents said NO. Respondent's knowledge on the occurrence of reproduction as per the class in which they are studying constitute 28 respondents said YES and 22 respondents said NO. Respondent's knowledge about way of HIV spreading as per the place of living, constitute 33 respondents said YES and 17 respondents said NO. Conclusion: Based on the findings it may be concluded that the knowledge among the adolescent girls about reproductive health awareness, it was found that the knowledge of reproductive health awareness was limited among the adolescent girls.

Keywords: Awareness, Reproductive Health, Adolescents

\footnotetext{
${ }^{1}$ Master of Social Work, Department of Social Work, Pondicherry University, Puducherry, India

${ }^{2}$ Psychiatric Social Worker, Department of Psychiatry, Post Graduate Institute of Medical Education Research (PGIMER), Chandigarh, India

*Responding Author

(C) 2016, B Pavithra, M Senthil; licensee IJIP. This is an Open Access Research distributed under the terms of the Creative Commons Attribution License (http://creativecommons.org/licenses/by/2.0), which permits unrestricted use, distribution, and reproduction in any Medium, provided the original work is properly cited.
} 


\section{Knowledge of Reproductive Health among School Going Adolescents Girls}

"Reproductive health is a state of complete physical, mental and social well-being and not merely the absence of disease or infirmity, in all matters relating to the reproductive system and to its functions and processes... It also improves sexual health, the purpose of which is the enhancement of life and personal relation, and no merely counselling and care related to reproductive and sexually transmitted diseases" (WHO, 1996). The above definition of reproductive health contained in the programme of the International Conference on Population and Development (ICPD), Cairo is an improved version of the World Health Organization's technical definition, which was accepted by the United Nations general assembly. It is being followed by government and voluntary agencies world over and also utilized as a functional definition for the present study. The reproductive health thus includes a much wider area than only physical wellbeing. Reproductive health addresses the physical, social, emotional and psychological dimensions of sex and reproduction and not just the presence or absence of disease of reproductive organs. The proponents of the reproductive health framework believe that reproductive health is inextricably linked to the subject of reproductive rights and freedom. Also, the reproductive health concept extends beyond the narrow confines of family planning to encompass all aspects of human sexuality and reproductive health needs during the various stages of the life cycle. ICPD (International Conference on Population and Development Program) declares that all countries "should protect and promote the rights of adolescents to reproductive health awareness, information and care and greatly reduce the number of adolescent pregnancies". The present study on reproductive health awareness is an attempt to respect and care about one's basic needs contributing to healthy body and mind. This becomes most crucial now, due to rapid demographic changes, media, and globalization. It is an individual's decision to reproduce or share physical expression. With growing individual autonomy and participation of adolescents it becomes a responsibility of the socializing agents to provide a guiding light towards a bright and stable future. The present concept of reproductive health awareness saw a scientific and global beginning with population studies and population education. It focused on developing individual's framework towards population and its impact on oneself. As defined by UNESCO seminar (1970), population education is an awareness programme which provides for a study of the population situation in a family, community, nation and the world, with the purpose of developing in the students rational and responsible attitude and behaviour towards that situation (Swamy, 2005). The status of girls and women in society and how they are treated or mistreated is a crucial determinant of their reproductive health. Educational opportunities for girls and women powerfully affect their status and the control they have over their own lives and their health and fertility. The empowerment of women is therefore as essential element for health (International Population Conference 1994). There are various studies conducted to assess the knowledge level of adolescents towards reproductive system and organs and awareness regarding sex knowledge on adolescent girls (16- 20 years) found that awareness regarding HIV/AIDS among adolescent girls is very low, adolescent girls also back adequate knowledge about sexual matter and contraception which results in early pregnancy, increased risk of STD infections, maternal morbidity and mortality and unsafe abortions. According to WHO, 250 


\section{Knowledge of Reproductive Health among School Going Adolescents Girls}

million new cases of STD occur worldwide each year with a high rate in 16-19yrs age group. Young people are at risk of HIV/AIDS because they are in the transition phase of their life. Hence these young people have the rights to understand the changes they are going through and to develop skills of forming healthy and responsible relationship. Many diseases can occur by lack of awareness, myths; hence there is need for creating awareness about reproductive health among the vulnerable groups.

\section{Reproductive health awareness:}

The Institute for Reproductive Health at Georgetown University conceptualized the Reproductive Health Awareness approach based on its work in natural family planning and fertility awareness. This cohesive approach helps community, educational, and health organizations offer knowledge and skills development in body awareness and self-care, gender awareness, sexuality, and interpersonal communication to their clients. Health is "a state of complete physical, mental, and social wellbeing and not merely the absence of disease or infirmity (World Health Organization, 1946)." This World Health Organization definition, years ago, helped to broaden the view of health care beyond a narrow institution based, authoritarian model of care led by health professionals. Increasingly, the patient has moved from being a passive recipient of care to a client or consumer of care who weighs alternatives, seeks second opinions, and assumes responsibility for prevention through diet, exercise, early treatment, and injury prevention measures. Though health education has become increasingly available through schools, community groups, mass media, the Internet, and other sources, many clients still do not have access to the high quality, reproductive-health information needed throughout their lives. This information would enable them to have optimum health, relaxed enjoyment of their sexuality, and understanding of how cultural values may help or hinder their reproductive and sexual health.

\section{Definition of Reproductive Health Awareness}

Reproductive Health Awareness is an approach designed to help people learn to observe their own bodies, understand its normal changes, and know what is healthy and typical for them. It helps people think about and understand cultural factors (such as gender and sexuality) that influence their reproductive health. It also helps people communicate appropriately with partners, healthcare providers, their children and parents, and others about reproductive health concerns, and make decisions that can have a positive effect on their reproductive health. Through Reproductive Health Awareness, people can learn to appreciate the regular functioning of their own bodies and reproductive systems, and use self-observation and an understanding of reproductive health to choose healthy behaviours, advocate for themselves, seek medical attention when needed, and communicate appropriately with healthcare providers. Since people who are aware of their reproductive health also understand what is normal for both men and women at different ages, they can actively participate in maintaining the health of their partners and children. This approach emphasizes empowering and involving both women and men in 


\section{Knowledge of Reproductive Health among School Going Adolescents Girls}

reproductive health issues and the family and community in equitably allocating health resources and being responsible for actively participating in their own health care. These emphases are supported by the mandate of the United Nations conferences in Cairo and Beijing and by other groups of governments and NGOs that have addressed these issues. No one group has the time, access, talent, or resources to teach all people all they need to know for a lifetime of health learning. The Reproductive Health Awareness approach can be taught by a variety of organizations including community, educational, and health groups. It is an approach that can be integrated into ongoing programs, and coordinated with other community programs with complementary interests to help address a broad range of reproductive health topics throughout life.

\section{Four pillars of reproductive health awareness:}

The Reproductive Health Awareness approach is based on four foundational supports that are referred to as "pillars." Each pillar supporting RHA is crucial on its own, but only when the pillars are combined is the RHA approach strongest and most effective.

\section{Body Awareness and Self-Care}

How we are taught to care for and respect our bodies influences our self-esteem, our views of how to treat the body, and how we view sexuality. Learning normal growth and development (for example, maturation of the body, fertility awareness, signs of disease, etc.), preventative health practices (for example, immunizations, low fat diet, routine testicular and breast exam, etc.), and avoidance of high-risk behaviours (for example, smoking, unprotected intercourse, high speed driving, etc.), equips us with information that can change the course of our lives. Body awareness leads us to self-care, which is important for developing and maintaining good reproductive health throughout our lives.

\section{Gender}

We are born either female or male but as we grow up we learn how to act and relate to others as women and men. This learned behaviour is what shapes our gender identity and our roles as men or women in society. Gender awareness is looking at ourselves through the filter of our own culture. As we become more aware of gender issues we learn how women and men are valued, whether gender-based violence is tolerated, and what practices are unfair, dangerous, or limiting. Through gender awareness, we also learn about biological differences, socially and culturally defined roles, how our gender perceptions can affect our relationships, how we communicate, and opportunities for reproductive and sexual health.

\section{Sexuality}

Sexuality is an important part of each of us. It includes all the feelings, thoughts, and behaviours of being female or male, being attracted and attractive to others, being in love, as well as being in relationships that include sexual intimacy and physical sexual activity. What we learn about 


\section{Knowledge of Reproductive Health among School Going Adolescents Girls}

sexuality varies as we grow older, although at every age we should hear positive messages and learn respect for the powerful and beautiful ability to express ourselves through our sexuality. It is important that as individuals we establish our own safe and healthy sexual norms, understand the norms of our society, and work to eliminate behaviours that are violent and unsafe, making our societies healthier for all.

\section{Interpersonal Communication}

The ability to speak openly with our partners, children, parents, and peers profoundly affects our relationships with people. We need to be able to communicate without embarrassment to health providers, negotiate sexual behaviours with partners, teach children with respect, correct information, and handle verbal conflict before it leads to violent behaviour. We need to have the words and skills to communicate our joys and frustrations to those who share our space and lives. The goals of the Reproductive Health Awareness approach are to do the following-

- Empower people to understand and take action to meet their own reproductive healthcare needs

- Assist communities in understanding and achieving the benefits of high quality, accessible reproductive health care and information that meet the needs of community members

- Facilitate the incorporation of body awareness and self-care, gender, sexuality, and interpersonal communication into reproductive health programs

- Incorporate positive cultural beliefs and healthy practices into the teaching and understanding of reproductive health

Through program assessment, and the strengthening or integration of new components, the Reproductive Health Awareness approach has been integrated into a variety of ongoing programs. These include community-based programs, primary and secondary school curriculum development, counselling sessions, clinical health services, health promotion campaigns, and other areas. As we examine how to better serve our families and communities, the RHA approach contributes to informed, positive, skilled, and highly functional healthy individuals.

\section{Concept of adolescence:}

The term adolescence comes from Latin word. Adolescence means "to grow" or "to grow to maturity”. The term adolescence has a broader meaning. It includes mental, emotional \& social maturity as well as physical maturity; Adolescence is developmental transition between childhood and entering major physical cognitive and psychosocial change. According to Erikson, is a time of searching for one's identity. Data availability on adolescent's lack of uniformity in the age parameter for defining the group of adolescents is a major constraint. Adolescents are most often subsumed with youth or with children or with young adult. Different policies and programmes define the adolescent's age group differently. For example: adolescents in the draft youth policy have been defined as the age group between 13-19 years, under the ICDS 


\section{Knowledge of Reproductive Health among School Going Adolescents Girls}

programme adolescents girls are considered to be between 11-18 years; the constitution of India and labour laws of the country consider people up to the age of 14 as children; whereas the reproductive and child health programme mentions adolescents age is between 10-19 years is considered as age of adolescence. It is evident that in India, age limits of adolescents have been fixed differently under different programmes keeping in view the objects of that policy or programme. Keeping in view the characteristics of this age group, it is widely felt and recommended in preparing a profile of adolescents. Further, age group of 10-19 years is rarely considered as a age group in official statistics. In 2009, there were an estimate 1.2 billion adolescents in the world, forming around $18 \%$ of the global population. The UN defines an adolescent as an individual aged 10-19. The vast majority of the world's adolescents 88 percentage lives in developing countries. The least developed countries are home to roughly $16 \%$ of all adolescents. India is home to more than 243 million adolescents, 1.2 billion estimated number of adolescents (10-19 years) in the world (2009 estimate). 234 million estimate number of adolescents in India. About one quarter of India's population is adolescents.

\section{CHARACTERISTISTICS:}

1) Adolescence is an important period. Immediate effect on attitude and behaviour.

2) Adolescence is a transitional period during any transitional period the individuals status is vague $\&$ there is confusion about the roles the individual expected to play.

3) Period of change: the rate of change in attitude and attitude adolescence parallels the rate of physical change.

4) Adolescence is a problem age.

5) Adolescence is a dreaded age.

6) Adolescence is the time of unrealism.

7) Adolescence is threshold of adulthood.

\section{Scientific backgrounds}

Scientific background has been drawn from the perspective of various psycho-social theories existed in the field of adolescents and adolescence. The theoretical perspective reflected that adolescents physical, cognitive, and emotional development occurs within social institutions, including family, friends, and school. Therefore, understanding the nature of development necessitates understanding the social contexts in which it occurs. For adolescents, families, peers, and schools constitute the most important cultural contexts in which development unfolds. It is widely accepted that adolescents have the right to reproductive health education, partly because it is a means by which they are helped to protect themselves against abuse, exploitation, unintended pregnancies, sexually transmitted infections and HIV/AIDS. Reproductive health awareness is the process of acquiring information and training attitudes and beliefs about reproductive health issues. Reproductive health is not limited to the life transmission or reproduction as it includes four important dimensions: 


\section{Knowledge of Reproductive Health among School Going Adolescents Girls}

- Anatomy and biology with sex physiology, procreation and survival mankind;

- Social dimension with cultural influence, social norms and rules;

- Psychological dimension with gender issue, the personality construction and self-esteem; and

- Affective and relational dimension with feelings (love, desire), points of view and emotions.

Reproductive health awareness seeks both to reduce the risks of potentially negative outcomes from sexual behaviour like unwanted or unplanned pregnancies and sexually transmitted infections, and to enhance the quality of relationships. It is also about developing adolescents' ability to make decisions over their entire lifetime. It is necessary, in order to go beyond a prescriptive approach, and adopt a decidedly educational perspective. In this way, taking into account adolescent students' representations is an important part of the learning process. The interest of taking them into account in an HIV/AIDS education programme for students has already been underlined (WHO, 1999; WHO, 2006). Reproductive health education requires the teacher and parents representations also so that they could help adolescents build more relevant ones.

\section{Need of the study:}

Adolescents are the future productive citizen of the country. Most of the adolescent girls need awareness about sexual and reproductive health. In the study area students are not that much aware about reproductive health, based on this research has made attempt to describe the level of reproductive health awareness among the student of government school, puducherry.

\section{MATERIALS AND METHODS}

\section{Aim of study:}

- To study the level of Reproductive Health Awareness among Subramaniya Bharathiyar Government Girls. Higher. Secondary. School, puducherry.

\section{Objective of the study:}

1. To understand the knowledge level of reproductive health among adolescent girls.

\section{Specific objectives:}

1. To understand the level of awareness about puberty among adolescent girls.

2. To know about the level of awareness about sexually transmitted diseases among adolescent girls.

3. To understand the health problem faced by adolescent girls due to the onset of puberty.

The data collected from Subramaniya Bharathiyar Government Girls. Higher. Secondary. School, puducherry. The sample comprising 50 respondents of school going adolescents girls and used lottery method by adopting simple random sampling technique from the class of VIII, 
IX and XI(number 120). A pre structure questionnaire was used to collect the data from the respondents. The pre structured questionnaire was designed especially with the objective of the study. The questionnaire consists of 28 questions and it has consists of the following segments: Part - I: Socio-economic and Demographic variables. Part - II: Awareness level about puberty. Part - III: Awareness level about sexual transmitted diseases. Part - IV: Health problem during puberty.

Part - I: Socio-economic and Demographic variables. It includes respondents' age, class, religion, parents' occupation, monthly income, type of family, place of living, duration of studying in present school, place of resident ship.

Part - II: Awareness level about puberty: Level of communication with father, discussion about Personal matters, discussion about menstruation with mother, about puberty, causes of puberty, Stages of menstrual cycle, personal hygiene at the time of menstruation, about reproductive function, reproduction is occurring, class on puberty in school.

Part - III: Awareness level about sexually transmitted diseases: sexually transmitted disease four way of spreading HIV infection, knowledge about reproductive function being mandatory.

Part - IV: Health problem during puberty: enough rest during puberty, good diet after puberty, pain during menses, irregular menstrual cycle, stress during menstrual cycle, and consultation with doctor about menstruation problem

\section{RESULTS}

\section{Table-1: socio demographic variables}

\begin{tabular}{|c|c|c|c|}
\hline $\begin{array}{l}\text { Sl. } \\
\text { No. }\end{array}$ & Variable & Frequency & Percentage \\
\hline \multirow{5}{*}{1} & $\begin{array}{l}\text { Age of the respondents } \\
13 \text { years }\end{array}$ & 4 & 8.0 \\
\hline & 14 years & 12 & 24.0 \\
\hline & 15years & 8 & 16.0 \\
\hline & 16 years & 16 & 32.0 \\
\hline & 17 years & 10 & 20.0 \\
\hline \multirow[t]{3}{*}{2} & $\begin{array}{l}\text { Education of the } \\
\text { respondent: } \\
8^{\text {th }} \text { std }\end{array}$ & 15 & 30.0 \\
\hline & $9^{\text {th }}$ std & 15 & 30.0 \\
\hline & $11^{\text {th }}$ std & 20 & 40.0 \\
\hline \multirow[t]{2}{*}{2} & $\begin{array}{l}\text { Domicile: } \\
\text { Urban }\end{array}$ & 46 & 92.0 \\
\hline & Rural & 4 & 8.0 \\
\hline \multirow[t]{3}{*}{4} & $\begin{array}{l}\text { Religion: } \\
\text { Hindu }\end{array}$ & 45 & 90.0 \\
\hline & Christian & 3 & 6.0 \\
\hline & Muslim & 2 & 4.0 \\
\hline
\end{tabular}

(C) The International Journal of Indian Psychology, ISSN 2348-5396 (e)| ISSN: 2349-3429 (p) | 94 
Knowledge of Reproductive Health among School Going Adolescents Girls

\begin{tabular}{|c|l|c|c|}
\hline $\begin{array}{c}\text { Sl. } \\
\text { No. }\end{array}$ & \multicolumn{1}{|c|}{ Variable } & Frequency & Percentage \\
\hline 6 & $\begin{array}{l}\text { Type of family: } \\
\text { Nuclear }\end{array}$ & 40 & 80.0 \\
\cline { 2 - 4 } & Joint & 10 & 20.0 \\
\hline 7 & $\begin{array}{l}\text { Fathers occupation of } \\
\text { the respondents } \\
\text { Unskilled labour }\end{array}$ & 40 & 80.0 \\
\cline { 2 - 4 } & Government job & 4 & 8.0 \\
\cline { 2 - 4 } & Business & 6 & 12.0 \\
\hline
\end{tabular}

The above table shows the socio demographic profile of the respondent and it shows that majority of the respondents from the age group of 16 years (32\%), studied in class $11^{\text {th }}(40 \%)$, from urban background (92\%), Hindu in religion (90\%), from nuclear family (80\%), and respondent father were unskilled labours (80\%).

Table-2: Age of the respondent and their knowledge on puberty

\begin{tabular}{|c|c|c|c|c|}
\hline \multirow{2}{*}{ S.NO } & \multirow{2}{*}{$\begin{array}{l}\text { Age of the } \\
\text { respondent }\end{array}$} & \multicolumn{2}{|c|}{ Knowledge about puberty } & \multirow{2}{*}{ Total } \\
\hline & & Yes & No & \\
\hline 1 & 13 years & 1 & 3 & 4 \\
\hline 2 & 14 years & 9 & 3 & 12 \\
\hline 3 & 15 years & 7 & 1 & 8 \\
\hline 4 & 16 years & 11 & 5 & 16 \\
\hline 5 & 17 years & 10 & 0 & 10 \\
\hline \multicolumn{2}{|c|}{ Total } & 38 & 12 & 50 \\
\hline
\end{tabular}

The above table shows the cross tabulation of age of the respondents and their knowledge about puberty. At the age of 13 years from total 4 respondents 1 respondents said yes and 3 respondents said no, age of 14 years from total 12 respondents 9 respondents said yes and 3 respondents said no, in age of 15 years from total 8 respondents 7respondents said yes and 1 respondent said no and in age of 16 years from totally 16 respondents 11 respondents said yes and 5 respondents said no, in age of 17 years from totally 10 respondents all respondents are know about puberty. 
Table-3: Respondent's knowledge on the occurrence of reproduction as per the class in which they are studying

\begin{tabular}{|c|c|c|c|c|}
\hline \multirow{2}{*}{ S.NO } & \multirow{2}{*}{$\begin{array}{c}\text { Class of } \\
\text { respondent }\end{array}$} & \multicolumn{2}{|c|}{$\begin{array}{c}\text { Knowledge on the occurrence of } \\
\text { reproduction }\end{array}$} & \multirow{2}{*}{ Total } \\
\cline { 3 - 5 } & $8^{\text {th }}$ & Yes & 7 & 15 \\
\hline 1 & $9^{\text {th }}$ & 8 & 7 & 15 \\
\hline 3 & $11^{\text {th }}$ & 12 & 8 & 20 \\
\hline Total & 28 & 22 & 50 \\
\hline
\end{tabular}

The above table shows the cross tabulation of class of the respondent and their knowledge about how reproduction is occurring. At the class of $8^{\text {th }}$ std from total 15 respondents 8 respondents said yes and 7 respondents said no, class of $9^{\text {th }}$ std from total 15 respondents 8 respondents said yes and 7 respondents said no, in class of $11^{\text {th }}$ std from total 20 respondents 12 respondents said yes and 8 respondent said no.

Table-4: Respondent's knowledge about way of HIV spreading as per the place of living

\begin{tabular}{|c|c|c|c|c|}
\hline \multirow{2}{*}{ S.NO } & \multirow{2}{*}{ Place of living } & \multicolumn{2}{|c|}{$\begin{array}{c}\text { Know about way of HIV } \\
\text { spreading }\end{array}$} & \multicolumn{1}{|c|}{ Total } \\
\cline { 3 - 5 } & & Yes & 15 & 46 \\
\hline 1 & Urban & 31 & 2 & 4 \\
\hline 2 & Rural & 2 & 17 & 50 \\
\hline Total & & 33 & No & \\
\hline
\end{tabular}

The above table shows the cross tabulation of place of living of the respondents and their knowledge about way of HIV spreading. 46 respondents from urban background out of which 13 respondents said Yes and 15 respondents said No, 4 respondents from rural background out of which 2 respondents said Yes and 2 respondents said No.

Table-5: Type of family of the respondents and their knowledge on whether reproductive function is mandatory

\begin{tabular}{|c|c|c|c|c|}
\hline \multirow[t]{2}{*}{ S.NO } & \multirow[t]{2}{*}{ Type of family } & \multicolumn{2}{|c|}{$\begin{array}{l}\text { Knowledge on reproduction } \\
\text { function is mandatory }\end{array}$} & \multirow[t]{2}{*}{ Total } \\
\hline & & Yes & No & \\
\hline 1 & Nuclear & 38 & 2 & 40 \\
\hline 2 & Joint family & 10 & 0 & 10 \\
\hline \multicolumn{2}{|c|}{ Total } & 48 & 2 & 50 \\
\hline
\end{tabular}

The above table shows the cross tabulation of type of family of the respondents and their knowledge about reproduction function is mandatory. In nuclear family out of 40 respondents 38 respondents said yes and 2 respondents said No, and in joint family all the respondents (10) said yes. 


\section{FINDINGS}

- The socio-demographic details revealed that a majority of respondents were in the age group of 16 years (32\%), class 11 (40\%), Hindu in religion (90\%), from urban background (92\%), from nuclear family (80\%), and majority of the respondents fathers occupation were unskilled labours (80\%).

- Age of the respondents and their knowledge on puberty, constitute 38 respondents said YES and 12 persons said NO.

- Respondent's knowledge on the occurrence of reproduction as per the class in which they are studying, constitute 28 respondents said YES and 22 respondents said NO.

- Respondent's knowledge about way of HIV spreading as per the place of living, constitute 33 respondents said YES and 17 respondents said NO.

- Type of family of the respondents and their knowledge on whether reproductive function is mandatory, constitute 48 respondents said YES and 2 respondents said NO.

- The study find that (56\%) of the respondents were aware about the reproductive health.

\section{SUGGESTION}

Implications pertaining to the Research Study: This research study shows that there is no influence of selected demographic variables (i.e. age, class, place, father's occupation, income of the family and religion) on reproductive awareness among the respondents of the research study.

\section{National Policies and Programmes on Reproductive Health Education for Adolescents}

The major policies and programmes related to the sexual and reproductive health of adolescent girls in Pondicherry were studied by the researcher. Findings suggested that although steps have been taken in articulating a commitment to address many of the sexual and reproductive rights of adolescents, there remains a considerable gap between the commitments made in the policies and programmes, the implementation of these commitments.

- The National Population Policy has neglected to discuss whether it is advocating Services for all adolescents or exclusively for married adolescents.

- The National Youth Policy remains ambiguous about the extent to which services will be made available to the unmarried or to the girls.

- The National AIDS Prevention and Control Policy (2002) is largely focused on unmarried young people (students in school and college) and to a certain extent, married young men. Even though the Policy advocates reaching out-of-school youth, who obviously include both the unmarried and married, through networks of youth organisations, sports clubs, the National Service Scheme and Nehru Yuvak Kendras, the fact that most of these networks largely cater to young males suggests that unmarried out-of-school and married adolescent girls and young women are unlikely to be reached by the proposed programmes. The National AIDS Prevention and Control Policy is notably silent about the delivery of any specially packaged services for adolescents. 


\section{Knowledge of Reproductive Health among School Going Adolescents Girls}

- The National Health Policy does not contain any reference to adolescents' need for sexual and reproductive health services or counselling.

- The National Population Policy is clearly focused on the less controversial aspects of sexual and reproductive health, i.e., counselling and dissemination of information, but not quite as clearly on the provision of services to unmarried adolescents. In this Policy, adolescents are included as a target audience for community-level education campaigns about the availability of safe abortion services and the dangers of unsafe abortion, but they are not included as a target group for safe and legal abortion services. Also, while nutritional services (because of their link with subsequent safe pregnancy) and pregnancy-related care are recommended, other key services are not mentioned.

Findings reflected that various programmes have been adopted to raise awareness about sexual and reproductive health among adolescent girls.

- The Adolescent Education Programme has been implemented in only slightly more than two-fifths of secondary schools nationally (MOHRD, NACO and UNICEF, 2005). It has been observed that feedback from students who attended the programme was generally positive and the opportunity to explore sexual matters in a safe space appreciated by both girls and boys.

\section{Recommendations given by the teachers on imparting reproductive health education to adolescents}

Almost all the teachers suggested on the issues of reproductive health education. Most of them said that there should be school counsellors for providing reproductive health education. They recommended that:

- There is a need to appoint school counsellors in all schools. Proper funding is required to run programs related to reproductive health awareness.

- Purpose of imparting reproductive health awareness should be made clear to the adolescent students. There is a need to tell them about right and wrong, tell them about the Indian culture.

- Regular monitoring and evaluation is required to know that how the adolescents are utilizing the information. Bring modifications accordingly.

- Media has a significant role to play. There is a need to have provision of telephonic counselling.

- There is a necessity to encourage students to ask questions. Put a box in the school in which students can drop their queries and addressed by the experts later.

- There is a need to work in coordination with parents, teachers and government/policy makers. Like advertisements on HIV/AIDS, create awareness on reproductive health needs of adolescents. 


\section{Knowledge of Reproductive Health among School Going Adolescents Girls}

\section{Recommendation and policy implication:}

Based on the overall findings the following recommendations are suggested for policy makers and program managers in order to promote reproductive health awareness among the adolescent girls of Pondicherry. Health education should be promoted through adolescent education and extension programmes among younger adolescent in rural and urban areas to create awareness on reproductive health consequences of pre-marital sex as well as 'to prevent complications of reproductive and sexual health risks.

\section{CONCLUSION}

Based on the findings it may be concluded that the knowledge among the adolescent girls about reproductive health awareness, it was found the knowledge of reproductive health awareness was limited among the adolescent girls. Following recommendation are suggested for better health care of the adolescent girls: Health education should be incorporated in the curriculum which should be given through teaching, interpersonal communication, television, health camp, and specialist. Mobiles are very common among the adolescents, broadcasting of health massage would be effective through mobiles. Reproductive health problems should be discussed among adolescents girls, through and identification through organize health clubs, adolescents hub at school level and identify and solve their reproductive health problems through counselling with the help of specialist on time to time. Such Study should be promoted at school level with the help of Anthropologist and non government organization so that on the basis of the study result government can start school health programmes. Such educational intervention programs must be given due importance, which will help the adolescent girls to take care of their own health and protect themselves from the risk of Reproductive health problems.

\section{Acknowledgments}

The author appreciates all those who participated in the study and helped to facilitate the research process.

\section{Conflict of Interests}

The author declared no conflict of interests.

\section{REFERENCES}

Adinma. J. I. B (2000): contraception in teenage Nigerian school girls. Department of obstetrics and gynaecology.2000; 283-291.

Ahuja and Tiwari (1995) : Awareness on puberty changes among the adolescent girls. Journal of community medicine. J fam welfare 1995; 41:46-50.

Bhalkule,P.R.(1997) Rahate,N.P., Zodpey,S.P., entitled “AIDS awareness among rural Junior college students” national aids control organisation ;222-223.

Common wealth youth program(1997):entitle on "Adolescent reproductive and sexual health"

Dash (2004): titled on “reproductive health problems of unmarried adolescent girls”. 


\section{Knowledge of Reproductive Health among School Going Adolescents Girls}

Dehne. K.L and Riedner.G (2001) reviewed few studies in "Sexually Transmitted Infections among adolescents”. Reproductive health matters.2001 may;9(17):170-83.

Dejong. J (2005): "reproducrive health matters" sexual and reproductive health situation of young people,2005may;13(25):49-59.

Diclement.RJ (2005):“prevention and control of STIs among adolescents”, july14; 292(2):171-9.

EI-Tawila(1999): "knowledge, attitude and practices on reproductive health and life planning”. "Transition to adulthood": A National survey of Egiptian adolescent, cario: population counselling.

Family Health International (1997) :In a study entitled "Reproductive health of young adults".

George (2004): study on knowledge and attitude related to reproductive health of adolescents, journal of reproductive health, 2004; 12(4):199-122.

Gevelber and biro,(1999) entitled "adolescents and sexually transmitted diseases"1999 aug;46(4):747-66.

Harms et al., (1998): study titled "Perceptions and patterns of reproductive tract infections in a young rural population in Namibia” journal of applied psysiology.1997;82:1573-1583.

Joshi.B.N.et al (2006): entitle "Reproductive Health Problems and Help Seeking Behaviour Amoung Adolescents in Urban India” Indian journal of paediatrics, 2006,73(6):509-513.

Kumar, A. (1999) and Abraham, L :In the study on "Sexual experiences and their correlates among college students in Mumbai city”1999,25(3):139-146.

Liamputtong and Manderson.L(2002): entitled "Coming of Age in South and Southeast Asia: youth sexuality and courtship”(PP.1-12).

Nzioka(2004): In a study entiled“unwanted pregnancy and sexually transmitted infection among young women in rural Kenya”2004 jan;6(1):31-44.

Pallavi,P., et al (2000-2001): study on "knowledge, awareness, belief and practices on sexuality and reproductive health of adolescents in slum of Ahmedabad".

Panchand C, et al (2000): In their study on "sexually transmitted diseases among adolescents in developed countries" 2000; 32:24-32.

Patnam (2002): unfortunately the parents particularly in rural areas due to their unawareness

Ram.R (2006): the study on conducted in Kolkata on "reproductive track infections among female adolescent girls” Indian J Community Med 2006; 31:32-3.

Rohith E.A.et al (2001): the study entitle "female education adolescent sexuality and the risk of sexually transmitted infection in ariaal rendille culture"

How to cite this article: B Pavithra, M Senthil (2016), Knowledge of Reproductive Health among School Going Adolescents Girls, International Journal of Indian Psychology, Volume 4, Issue 1, No. 69, ISSN:2348-5396 (e), ISSN:2349-3429 (p), DIP:18.01.013/20160401, ISBN:978$1-365-45447-9$

(c) The International Journal of Indian Psychology, ISSN 2348-5396 (e) | ISSN: 2349-3429 (p) | 100 